Artemis Alexiadou*

\title{
Morphological and semantic markedness revisited: The realization of plurality across languages
}

https://doi.org/10.1515/zfs-2019-0004

\begin{abstract}
The paper investigates two related questions that concern the realization of plural morphology on nouns across languages. The first question is whether markedness in the sense of complexity in form goes hand in hand with complexity in meaning. In other words, since plural nouns are formally more complex than singular nouns, does that mean that they differ in interpretation? On the basis of experimental and theoretical investigations the claim is supported that plurals, although morphologically more complex than singulars, are semantically unmarked across languages. The second question is what regulates the presence of plural morphology in numeral-noun constructions across languages, in light of the proposal that plural appears on nouns in such constructions only if it is semantically unmarked. The paper offers an explanation of this distribution by adopting a dual system of agreement, which distinguishes between CONCORD and INDEX features. By looking at these two questions, the paper makes a contribution to the discussion of the relationship between semantic and morphological markedness.
\end{abstract}

Keywords: markedness, plural, numerals, maximize presupposition!, gender, definiteness

\section{Introduction: Plural formation across languages}

In languages that have a singular-plural contrast, the plural is always morphologically more complex than the singular. This is illustrated in (1) and (2) with examples from English and Turkish respectively:

\footnotetext{
*Corresponding author: Artemis Alexiadou, Institut für Anglistik und Amerikanistik, Humboldt-Universität zu Berlin and Leibniz-Zentrum Allgemeine Sprachwissenschaft, Berlin, Germany, e-mail: artemis.alexiadou@hu-berlin.de, ORCID: https://orcid.org/0000-0002-6790-232X
} 
(1) a boy

vs. boys

(English)

a car vs. cars

an elephant vs. elephants

(2) soru

vs. soru-lar

(Turkish)

'question' 'questions'

kalem vs. kalem-ler

'pen' 'pens'

fil vs. fil-ler

'elephant' 'elephants'

However, languages differ as to whether or not plural marking is required in the presence of numerals. Concretely, numerals in some languages, as is the case in Turkish, combine with bare nouns. In English, by contrast, the presence of plural morphology is obligatory in the context of a numeral, at least in standard varieties of English:

(3) two elephants

(English)

(4) iki fil/*-ler

(Turkish)

two elephant/-PL

'two elephants'

The contrast in (3)-(4) suggests that there are two types of languages. As Aronoff and Fudeman (2011: 6) point out, languages like Turkish “don't use plural morphology in contexts like this.” In his typological study Corbett (2000: 211) noted that "the numeral phrase is the most likely place for plural not to be required." In English, plural is required in the context of numerals greater than one, but also zero and decimals (zero books, 1,5 books), while in Turkish the noun appears bare in all types of numeral-noun constructions (henceforth NNCs). Lack of plural morphology in NNCs is found in typologically very diverse languages, e.g. Turkish, Hungarian, Georgian, Welsh, and even varieties of English. ${ }^{1}$

To address the cross-linguistic variation observed in (3)-(4), the following proposal has been formulated, most forcefully in the work of Bale et al. (2011a):

1 For instance, Poplack and Tagliamonte (1994) and Cheshire et al. (2015) report for AfricanAmerican English and Multicultural London English (MLE) respectively that numerals in these varieties occur with bare nouns, see (i) illustrating MLE:

(i) ten boy

(Cheshire et al. 2015: 10)

According to the electronic World Atlas of Varieties of English (eWAVE; Kortmann and Lunkenheimer 2013), plural is obligatory with numerals only in 33 out of the 76 varieties of English that are included in the atlas. 
In languages in which NNCs contain bare nouns, the meaning of the plural is different from the meaning of the plural in languages in which NNCs contain plural nouns.

(5) is important as it proposes to align a morpho-syntactic diagnostic with formal and semantic complexity and it basically implies that the plural does not have the same meaning in the languages in which we find a singular vs. plural contrast. Crucially then, if the meaning of plurality differs across languages, pointing to a semantic parameter, we need to i) determine how and why it differs, and ii) examine the consequences of this for the morpho-syntactic representation of plurality in particular and the morpho-syntax of noun phrases in general. Once this is achieved, an important contribution to the development of a morpho-semantic theory of number, as envisaged in the work of Harbour (2008), will have been accomplished.

This paper is a further contribution towards this direction. I will argue that plurals have a uniform interpretation across languages. Evidence for this will come from two sources: experimental work on plurality and theoretical work arguing for uniform semantics. As plurals will turn out to have identical semantics across languages, I will revisit the distribution in (3)-(4). I will argue, following proposals in the literature, that the cross-linguistic variation observed points to a split between plural-agreement and non-plural agreement languages. Support for this approach will come from differential marking effects in the context of plurality, the study of which informs the theory of agreement. I will then explore the sources that regulate the presence vs. lack of agreement.

The paper is structured as follows. In Section 2, I discuss different views on the relationship between the form and the meaning of plurality across languages. This discussion makes reference to the theory of markedness. In Section 3, I present experimental evidence in favor of uniform semantics for plurality. In Section 4, I discuss further data supporting the conclusion in Section 3. In Section 5, I reevaluate the distribution of plural marking in the context of numerals by adopting a dual agreement system, as developed in Landau (2016), building on Wechsler and Zlatić (2003). In Section 6, I turn to a discussion of differential marking effects. In Section 7, I offer my overall conclusions.

\section{On morphological and semantic markedness}

As detailed in Haspelmath (2006: 26), the term markedness has very many different senses in linguistics. Two of those are relevant for my discussion: the notion of 
formal/morphological markedness, which relates to the presence of overt encoding of a particular grammatical feature, and the notion of semantic markedness, which offers a specification of a semantic distinction. According to Haspelmath (2006: 26), both of these senses take markedness to involve some form of complexity. Let us see how these senses apply in the context of plurality.

My point of departure for the characterization of formal markedness concerning plurality is Universal 35 given in (6):

(6) Universal 35 (Greenberg 1963):

There is no language in which the plural does not have some non zeroallomorphs, whereas there are languages in which the singular is expressed only by zero.

According to (6), non-singular categories are marked categories. Related views have been expressed also by Jakobson (1968), who basically views zero expressions of features as belonging to the unmarked member of a category. ${ }^{2}$

Semantic markedness on the other hand, as defined by Bale et al. (2011b: 201), restricts the uses of the marked member of an opposition: "A noun with an unmarked feature can often be used to quantify over more types of entities than a noun with a marked feature." (And see Jakobson 1971; Greenberg 1966; Croft 2002; Silverstein 1986 for further discussion.) This led Bale et al. (2011b: 204) to conjecture that "unmarked features cannot affect interpretation, whereas marked features can." In the context of plurality, this means that the plural, if it is semantically marked, it must have a more restricted use.

An important question then is the relationship between morphological and semantic markedness. Ideally, as Bale et al. (2011b: 206) state, "the great hope is that if the semantic diagnostics tell us a particular category is unmarked, the morphological ones should as well." We thus expect, that, since plural is always expressed with a particular exponent, it should mean something different from the singular and be semantically marked. In other words, morphological markedness should correlate with semantic markedness. Nevertheless, matters are not that simple. Importantly, it has been pointed out that the English plural has two interpretations:

a. Mary saw a horse.

b. Mary saw horses.

(English)

(Farkas and de Swart 2010: 2)

2 There might be a correlation with frequency, see Haspelmath and Karjus (2017), Kurumada and Grimm (2017) for recent discussion, but I will not discuss this here. 
In (7), the singular refers to a single entity, while the plural refers to more than one entity. This interpretation is referred to by some researchers as the exclusive plural (while others use the terms marked or strong). However, in downward entailing contexts, the plural receives a number neutral interpretation, as shown in (8) (i. e. it can mean one or more) (see van Eijck 1983; Hoeksema 1983; Krifka 1989; Sauerland 2003; Spector 2007 among others):

(8) Every guest who brought presents left early.

Compatible with guests bringing only one present (as long as such guests left early)

This type of interpretation is referred to by some researchers as the inclusive plural (while others use the terms unmarked or weak). In this paper, I will use the terms exclusive vs. inclusive to refer to the two readings exemplified in (7-b) and (8).

The availability of two interpretations for English plurals has generated a lot of discussion in the literature: how do the two interpretations of the plural come about? Are they available across languages? Are (7-b) and (8) a case of ambiguity or do they involve pragmatic reasoning? In this paper, I will adopt the pragmatic account of plurality, and the reader is referred to the work of Renans et al. (2017) for arguments against the ambiguity approach (and see Farkas and de Swart [2010], Kiparsky and Tonhauser [2012], Marti [2017] among others for alternative analyses). According to the pragmatic approach to plurality, the plural carries no inherent presupposition and its exclusive interpretation is a matter of pragmatics. This means that the plural can include singular reference in its denotation. However, it is not the case that plurals are always interpreted as inclusive. For instance, the examples in (9) sound odd. This has been argued to be a pragmatic blocking effect, as discussed in Krifka (1989), Sauerland (2003) and subsequent work. The pragmatic blocking effect follows from the principle of Maximize Presupposition! (Heim 1991), which regulates the competition between two forms that have different semantic presuppositions:
a. \#My noses itch.
b. \#I have noses.

\section{Maximize Presupposition!}

Among a set of alternatives, use the felicitous sentence with the strongest presupposition.

(Chemla 2008: 142)

From the perspective of (10), and assuming that the singular form is in competition with the plural form, the examples in (9) are odd as humans possess only one nose, and thus the singular form satisfies the presupposition of the utterance. 
Bale and Khanjian (2014) and Mathieu (2014) among others argue that there are languages with exclusive only plurals. Moreover, Bale et al. (2011b) show that there is a systematic correlation between the type of interpretation plurals may have in a language and the availability of morphologically marked plural nouns in NNCs. From these authors' perspective then, there are two types of languages: ${ }^{3}$

1. Type I includes English and generally languages in which the plural has an inclusive interpretation and exclusive interpretations are the result of pragmatic reasoning. In these languages, nouns in NNCs surface with plural morphology.

2. Type II includes Turkish, and generally languages where the plural has an exclusive only interpretation. In this group, nouns are bare in NNCs.

Importantly, in both types of languages there is one form that is always semantically unmarked: in type I languages it is the plural. In type II languages, it is the bare form (labeled general number in Corbett [2000], and transnumeral in Greenberg [1974]). In other words, if a language has true bare nouns with a general number interpretation, then in this language nouns appear bare in NNCs. Moreover, such a language has exclusive only plurals. This discussion leads to the formulation of the parameter in (5) from the introduction, repeated in (11).

(11) In languages in which NNCs contain bare nouns, the meaning of the plural is different from the meaning of the plural in languages in which NNCs contain plural nouns.

Evidence for the correlation between general number and presence of bare nouns in NNCs comes from the following data. As shown in (12), in Turkish the bare form has the meaning one or more. As we have already seen, in this language the plural is incompatible with numerals, as illustrated in (13):

(12) Kitap al-di-m

(Turkish)

book buy-PAST-1sG

'I bought a book/books.'

(13) a. iki çocuk

(Turkish)

two boy

'two boys'

b. *iki çocuk-lar

two boy-PL

3 Cf. Bouchard (2002), Rijkhoff (2002), Déprez (2005), Wiltschko (2008) among others for other parameterization approaches. Alexiadou (to appear) takes issue with the particular parametrization view put forth in Wiltschko (2008). 
Hungarian is another language providing evidence for this correlation. In pseudoincorporation contexts, where object noun phrases appear in fixed positions, the bare form can have the meaning one or more, as shown in (14):

$$
\begin{aligned}
& \text { Mari verset olvas. } \\
& \text { Mari poem.Acc read } \\
& \text { 'Mari is reading a poem/poems.' } \\
& \text { (Farkas and de Swart 2003: 5) }
\end{aligned}
$$

(Hungarian)

As was the case in Turkish, the plural is incompatible with numerals, see also Dékany (2011):

$$
\begin{aligned}
& \text { a. hét virág } \\
& \text { seven flower } \\
& \text { 'seven flowers' }
\end{aligned}
$$

b. *hét virág-ok

seven flower-PL
(Turkish)

Similar observations have been made for Creole languages. For instance, as stated in Kihm (2007: 159), in Guinea-Bissau Portuguese Creole "genuine bare nouns exist, with no value at all for Number. A correlate of this state of affairs is that nouns in the scope of numerals or plural quantifiers are not marked for plurality," as illustrated in (16):

$$
\begin{aligned}
& \text { sinku kabra }\left({ }^{\star} s\right) \\
& \text { five goat(.PL) } \\
& \text { (Kihm 2007: 159) }
\end{aligned}
$$

(Guinea-Bissau Portuguese Creole)

In English, the only environment where nouns appear with a number neutral interpretation is in the context of compounds, e. g. stamp collector, which have been recently argued to contain a phrasal non-head (crucially an nP, see Iordăchioaia et al. 2017 for discussion). Typically, languages that do not have obligatory marking of plurality on nouns in NNCs have classifiers, which are possible but not obligatory also in Hungarian and Turkish.

The above examples support the correlation between the existence of bare forms and the unavailability of plural nouns in NNCs. The question that arises then is whether this aligns with semantic markedness, i. e. whether plurals in languages that have genuine bare nouns necessarily have the interpretation more than one, as suggested by (5). If Bale et al. (2011a) are right with respect to how the morphological and semantic diagnostics should align, then type II languages should have exclusive only readings in contexts where English allows for inclusive interpretations (cf. Marti 2017). This is now an interesting test-case both from a theoretical point of view and from a developmental perspective. 
From a grammatical perspective, testing these environments helps determine which of the two members of the opposition is the semantically marked one. In addition, this discussion informs theories of the morpho-syntax of plural. If indeed plurals differ semantically across languages, a way to offer a morpho-syntactic correlate of this difference is to propose that there are many a plural. According to this view, the plural must be in different positions along the functional spine of the noun phrase and the different loci in the spine are responsible for the different readings of the plural (e. g. Acquaviva 2008; Wiltschko 2008; Alexiadou 2011; Mathieu 2014; Kramer 2015 and others).

Recently, such a view has been defended in Mathieu (2014), who argued that in languages where the plural is interpreted as exclusive only, the head introducing plurality is a different one from the one introducing plurality in English. Mathieu (2014) employs the structure in (17) to account for differences in the interpretation of plurals. (17) has been put forth in Borer (2005) and sees a division of labor between Quantity and Division, cf. Heycock and Zamparelli (2005): QuantityP introduces the counting function and hosts numerals, and according to Borer (2005: 96) is responsible "for the assignment of quantity to stuff or to divisions of it.” The dividing function is introduced in Div ${ }^{\circ}$. In English, Div ${ }^{\circ}$ is the locus of plural morphology and the indefinite article; for this reason, in English nouns that combine with numerals, irrespectively of their cardinality (greater than one, zero or 0,5 ), surface with plural morphology. Importantly, for Borer (2005), plural portions out mass and has exactly the same contribution as classifiers in languages such as Chinese, in which count nouns obligatorily first combine with classifiers in order to appear in NNCs:

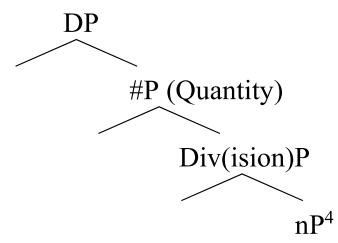

While for Borer (2005), plural morphology is under Div, Mathieu (2014) argues that this is so for the inclusive plural. Exclusive only plurals are introduced under \#, i. e. they are counting plurals, and thus are incompatible with numerals. His argument was based on Arabic collective nouns, which receive an individual interpretation via singulative morphology. The singulative form can then be

\footnotetext{
4 I use the label nP instead of NP here, following standard assumptions in Distributed Morphology, according to which all nouns are complex and involve the combination of an acategorial root with a categorizer, namely $n$.
} 
pluralized and Mathieu argues that the plural of a singulative has only the exclusive interpretation. He thus proposes that singulative morphology is under $\operatorname{Div}^{\circ}$, since it introduces division, while the plural of singulatives is located under \#. Dékány (2011) proposed an analysis of Hungarian plurals as realizing both Div ${ }^{\circ}$ and \#. In such a system, bare (and number neutral nouns) are just nPs. This discussion then suggests that determining which of the readings of the plural is available cross-linguistically has consequences for its morpho-syntactic representation.

From a developmental perspective, the predictions the various approaches to plurality make are related to Maximize Presupposition! and help discriminate between the ambiguity vs. pragmatic account. If children have difficulties with pragmatic principles, we expect them to show some sort of delay in grasping the interpretation of plural. In the next section, I will turn to a brief discussion of this prediction. In Section 4 and Section 5, I will be looking at the grammatical analysis of plural in greater detail.

\section{Experimental evidence}

The picture that emerges from the theoretical literature can be summarized as follows: a) the plural is semantically unmarked in English. b) By contrast, if (5) holds, the plural should be semantically marked in e. g. Turkish. Importantly for my discussion, if the plural is semantically unmarked, it is compatible with singular reference and pragmatic blocking restricts its use. If, however, the plural is semantically marked, it is never compatible with singular reference. From the perspective of (5) then, we expect a clear difference between English and Turkish type languages.

These hypotheses were tested by Sauerland et al. (2005), Pearson et al. (2011), Yatsushiro et al. (2017), Renans et al. (2017), and Yatsushiro et al. (2018) among others with children and adults across languages. The pragmatic account predicts that in the case of semantic unmarkedness, adults should reject the plural use in singular reference, but it should require some extra effort. Children, however, should accept the plural use in singular reference. By contrast, in the case of semantic markedness, adults should reject the plural use in singular reference more readily, and children should never accept the plural use in singular reference. Children are expected to behave differently, as they tend to accept interpretations that are blocked by e.g. scalar implicatures. As discussed in Yatsushiro (2008), children have difficulties with Maximize Presupposition! and these difficulties have their source in the pragmatic mechanism. 
Yatsushiro et al. (2017) present results of three experiments: experiment one tested wh-question comprehension across 18 languages, and the other two experiments were conducted specifically to examine children's comprehension of plural in German. Experiment one used the picture matching task, in which a participant was presented with four pictures and had to choose the picture that matches the answer to the question asked. Important in this case were the number errors participants produced. A number error is identified when the intended subject is plural (e. g. the fairies), but the participant understands it as singular (the fairy) and as a result picks the picture in which a singular referent is depicted. We found out that this type of error amounts to between ca. $10 \%$ to ca. $50 \%$ of all the responses. The number error was observed in every participating language, and it was independent of the form of the plural morphology. We concluded that this supports the view that plural meaning is unmarked, and therefore compatible with the singleton referent context, as this can explain why number errors arise. For experiments two and three, we tested 42 monolingual German speaking children (3;6-8;6, $M=5 ; 10)$ and 11 monolingual German speaking adults. Experiment two was a question task and was presented on an iPad using slides. After seeing each slide, the participant was asked a yes/no question about the picture, containing a plural expression. The test items included expressions where plural was used when there was a singleton referent (e. g. does this girl have noses?). In experiment three, participants saw a slide with three cards, one of which was covered. The participants were told that they would hear a recording that tells the participants to point to one of the cards, and their task is to follow the direction and identify which card they were supposed to point to. This paradigm was originally used in Pearson et al. (2011) for plural comprehension of adult English speakers. We adjusted the items and expressions in order to only include nouns whose plural morphology is either - $e$ or -en. In experiment three, in the test case participants would see e. g. a table and a carrot on the two open cards, and one card that is covered. The audio stimuli for this slide would be Zeig mir die Karte mit Tischen 'Show me the card with tables.' If the participant accepts the use of plural with a singleton referent, they should choose the card with a single table on. If the participant does not accept the use of plural with a singleton referent, on the other hand, they should choose the covered card. We further hypothesized that when the use of plural in a singleton context is rejected by the child in experiment two, the same child should choose the covered (target) card in the experiment three. In experiment two, adults rejected the use of plural in a singleton referent context around $83 \%$ of the time (20/30), whereas children rejected the same context around $26 \%$ of the time (33/126). In experiment three, most of the adult participants chose the target card, whereas the opposite is true for children. In conclusion, our results showed that young children accept the use of plural expressions in a singleton referent 
context, more readily than adults do. This is so independently of the form of the plural. Moreover, we showed that language development drives the responses in the sense that younger children accept the use of plurals for single reference more so than older children. The reader is referred to Yatsushiro et al. (2017) for further details and a list of the languages we tested in experiment one.

As in our (2017) study we had no language of the Turkish-Hungarian type, Yatsushiro et al. (2018) carried out a follow up experiment by using the covered card task on children's acquisition of plural in Hungarian and Turkish (mean age 5,5 and 5,0 respectively). This study yielded similar results: children in Turkish and Hungarian accept the plural in a singular context and show no interesting differences from their German counterparts. It is important to point out that Renans et al. (2017) also tested Turkish-speaking adults and 4-6-year-old children on the interpretation of plurals in upward- and downward-entailing contexts by using a different type of methodology from ours. Yet their results, similar to ours, show that Turkish children prefer unmarked interpretations in contrast to adults.

Such findings thus do not provide support for the parametric view in (5). ${ }^{5}$ As we will see in the next section, this is in line with theoretical descriptions of plurality in both Hungarian and Turkish and of type II languages in general.

\section{Semantically unmarked plurals cross-linguistically?}

Farkas and de Swart (2010) have shown that in downward entailing contexts, Hungarian plurals give rise to similar effects as their English counterparts. This means that the Hungarian plural is not different from its English counterpart, and thus the morpho-syntactic trait cannot be the signal for a deeper semantic plural parameter.

$$
\text { If you have children, please raise your hand. (one or more) }
$$

Halátta valahalovakat, szól. (Hungarian)

if see.PAST.2sG ever horse.PL.Acc Say.IMP

'If you have ever seen horses, say so.' (one or more horses)

(Farkas and de Swart 2010: 9)

5 Note here that these results cannot be explained by assuming that the plural is acquired later than the singular, since in e. g. both English and Turkish, children master plural morphology by the age of three, see Clark and Nikitina (2009), and Acarlar and Johnston (2011). 
The Turkish plural has been controversially discussed in the literature. Recently, Sağ (2018) demonstrates that in downward entailing contexts, Turkish plurals are identical in meaning to their English counterparts.

$$
\begin{aligned}
& \text { Erkek-ler tarafindan aldat-ll-an } \\
& \text { man-PL by cheat-PASS-REL } \\
& \text { herkes biz-e katıl-abil-ir. } \\
& \text { everybody we-DAT join-ABIL-AOR }
\end{aligned}
$$

'Everyone who has been cheated by men can join us.' (one or more men)

(Sağ 2018: 311)

This type of behavior is observed in other type II languages as well. Work on Balinese (an Austronesian language) by Arka and Dalrymple (2017) shows that the plural in this language is also unmarked, although the language behaves similar to Turkish in NNCs using bare nouns. Note that Balinese forms plurals via reduplication, suggesting that the effect is independent of the form of plurality.

a. Nyoman ningalin njek njekan buron.

(Balinese)

Nyoman AV.see footprint-REDUP animal

'Nyoman saw animal footprints (more than one).'

b. Nyoman sing ningalin njek njekan buron.

Nyoman NEG AV.see footprint $\sim$ REDUP animal

'Nyoman didn't see even a single animal footprint.'

(Arka and Dalrymple 2017: 313)

We can thus conclude that the plural is semantically unmarked, although it is morphologically marked. We have suggestive evidence that perhaps this is universally so, and this is independent of the form of the noun in NNCs. The consequences of this for the morpho-syntax of plural are straightforward. In the previous section, I introduced Mathieu's (2014) structure of the noun phrase, according to which exclusive plurals are located in \#. Since, however, there are no semantic differences between English and Hungarian or English and Turkish for that matter, we must conclude that plurals occupy the same position across languages and that there is no such thing as many a plural. Plural morphology is located in Div ${ }^{\circ}$ and may be interpreted as inclusive across languages.

Notice now that our discussion raises an important question for the pragmatic blocking account: why should type II languages have two semantically unmarked forms, both the plural and the bare noun (see Arka and Dalrymple 2017)? However, in certain type II languages a complex interaction between number and semantic features such as animacy and definiteness is observed, suggesting that in certain contexts plural or singular forms have indeed more restricted uses. For example, 
in Western Armenian, there is a strict correlation between marking of definiteness and singular interpretation, see Bale and Khanjian (2014). Bliss (2004) reports a similar state of affairs for Turkish. For instance, as also shown in Sağ (2018), bare NPs in subject position are interpreted as strictly singular. The same holds for NPs marked accusative, as in (22-b):

a. Çocuk eve-e koş-tu.

(Turkish)

child home-DAT run-PAST

'The child ran home.'

Not: The children ran home.

b. Ali kitab-ı oku-du.

Ali book-ACC read-PAST

'Ali read the book.'

Not: Ali read the books.

(Sağ 2018: 310)

Importantly, as Bliss (2004) shows, it is not the case that all bare nouns in Turkish are interpreted as having general number. As she points out, it is more likely that nouns like banana and seed will have general number interpretations than nouns such as book and house. Furthermore, there is an animacy effect: as Bliss points out, inanimate nouns in Turkish can have a general interpretation, while animate nouns seem to have strictly singular interpretations.

Plural is sensitive to definiteness features as well. In Turkish, the plural may be used in constructions with numerals to mark definiteness, as shown in (23). Bale and Khanjian (2014) discuss similar facts in Western Armenian. I will come back to that in Section 6.
a. kark harami
forty thief
'forty thieves'
b. Krk Harami-ler
forty thief-PL
'The Forty Thieves' (from the Ali Baba legends)
(Underhill 1979: 125)

(Turkish)

Summarizing, the semantic parametric approach in (5) cannot be maintained. Type II languages are characterized by the inclusion of bare nouns in NNCs. Moreover, in several type II languages, plurality interacts with definiteness and animacy, a point I will look at closely in Section 6. The question then is why this happens only in type II languages. Finally, what explains the morpho-syntactic trait of type II languages, i. e. the fact that numerals cannot co-occur with plural 
nouns, unless the noun is interpreted as definite as in (23-b)? I turn to a discussion of this issue in the next section. ${ }^{6}$

\section{Type II languages: *Numeral-Noun plural}

\subsection{Are numerals different?}

In the structural representation of the noun phrase discussed in Section 2, see (17), repeated here in (24), the locus of numerals is in \#P. Standardly, numerals are seen as adjectives and analyzed as occupying the specifier position of \#P, see e. g. Giusti (2002), Alexiadou et al. (2007) for an overview.

(24)

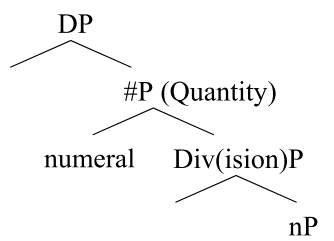

However, Borer (2005) leaves open the possibility that numerals may merge in the syntactic structure either as heads or specifiers. The head option is explicitly pursued for most Hebrew numerals and other quantifiers. If numerals are indeed heads, then NNCs can be viewed as a kind of partitive construction, where the numerals are heads taking an XP complement, as illustrated in (25), echoing early transformational analyses of NNCs, see also Mittendorf and Sadler (2005) and Ionin and Matushansky (2006) among others:

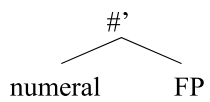

Ionin and Matushansky (2006) argue that since in some languages, e. g. Slavic and Finnish, the noun in the NNC bears a case distinct from that of the numeral, as will be detailed in Section 6.2, structure (25) should be assumed also for English. By contrast, Danon (2012: 42) argues that both types of structural analyses of numerals are on the right track and apply to different languages. In particular, the head-complement structure in (25) is to be assumed for languages such as

6 Rijkhoff (2002) proposes a different type of analysis for type II languages, which I will not discuss here in detail. The basic idea is that these languages have what he labels set nouns. In his terms the plural marker in this type of languages is a collective marker and not strictly speaking a marker of plurality. The type of implementation offered in Section 6 is, I believe, in a position to capture this intuition. 
Slavic and Finnish in which DP internal case assignment takes place that excludes the numeral. In all other languages, numerals should be analyzed as specifiers of \#P, i. e. even in Hungarian and Turkish. ${ }^{7}$

Danon (2012) further argues that numerals in NNCs lack morpho-syntactic plurality and proposes that the spec-head configuration is impossible if the numeral has morpho-syntactic plurality. Evidence for this comes from the observation that in e. g. Hungarian or Turkish NNCs the verb agrees with the head nouns and bears singular morphology, illustrated here with a Hungarian example. This suggests that the numeral lacks plural features and moreover that the head noun and the numeral are part of the same extended projection (see Alexiadou et al. [2007] for discussion). In the absence of numerals, a plural noun agrees with the predicate, as shown in (26-b):
a. A két lany megérkezett
(Hungarian)
the two girl arrive.PAST.3SG
'The two girls have arrived.'
b. A lány-ok megérkezt-ek
the girl-PL arrive.PAST-3PL
'The girls have arrived.'
(Szöke 2018: 927, exx. [893a], [893a'])

According to Ortmann (2000: 254), in type II languages "the verb is incapable of showing plural agreement, if the subject contains a numeral."

Further support against aligning the structure of NNCs with that of partitives is discussed in Danon (2012: 23), who points out that in complex NNCs (prepositional or those involving extra case morphology), languages that lack plurals in simple NNCs allow or even require plural marking on the noun. For instance, Welsh lacks plural morphology on nouns in NNCs, as shown in (27-a), see Mittendorf and Sadler (2005) for discussion. Welsh, however, uses a type of partitive construction with a meaning very similar to that of numeral-noun in (27-a), as shown in (27-b), where the noun is obligatorily marked for plural:

$$
\begin{aligned}
& \text { a. deg llun } \\
& \text { ten picture } \\
& \text { 'ten pictures' } \\
& \text { (Borsley et al. 2007: 163) }
\end{aligned}
$$

7 As discussed in Ackles (1997), in Old English NNCs had a different structure: nouns after numerals inflected for genitive case, e. g. sume hundred scipa 'some hundred ships_gen.pl'. In Present Day English (PDE), however, we no longer have an N-N dependency, which points to a case of reanalysis. This opens up the possibility that PDE retains the plural marking of the older partitive construction in the Spec-Head numeral-noun configuration. 
b. táir o ferched

three of girls

'three girls'

(Borsley et al. 2007: 170)

Since across languages the PP partitive construction includes nouns with plural morphology, Danon argues that in this case the whole extended projection of the noun is included in the complement domain of the numeral. I will come back to this discussion in Section 6.2.

A further explanation that comes to mind is to propose that in type II languages, numerals function like plural markers, as was put forth by Borer (2005) for Hungarian. This means that in addition to their being associated with the counting function, they may also take over the task of division. However, this view offers no explanation as to why plural marking is also disallowed in the presence of other quantifiers in Hungarian, and Kornfilt (1997) reports similar facts for Turkish. This would suggest that all quantifiers in Hungarian and Turkish are dividers, i. e. they create count nouns, though they may all be counters in Borer's system.

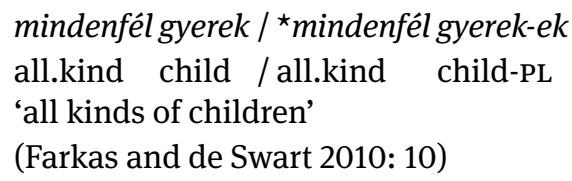

It is also not clear how we could account for the fact that in e. g. Hungarian classifiers can occur with numerals, while plural marking cannot co-occur with classifiers, as illustrated in (29) from Dékany (2011). If classifiers have a function similar to that of plural marking, as Borer (2005) forcefully argued, and numerals may be dividers in Hungarian, this distribution is not straightforwardly explained.
a. ez-ek a ( ${ }^{\star}$ rúd) szalámi-k
this-PL the $\mathrm{CL}_{\text {stick }}$ salami-PL 'these sticks of salami'
b. hét szál virág seven $\mathrm{CL}_{\text {thread }}$ flower 'seven flowers'
c. hét virág-( $\left.{ }^{\star} \mathrm{ok}\right)$ seven flower- PL 'seven flowers' (Dékany 2011: 235-236) 
strictive in languages such as English. Note, however, that in their discussion Bale et al. focus on numerals greater than one. As we have seen in this paper, the behavior of nouns in NNCs includes numerals greater than one, but also zero and decimals. It is not clear to me how Bale et al.'s analysis would extend to these cases as well.

\subsection{Agreement}

In the previous section, I adopted the structure in (24) for numerals across languages. The patterns of NNCs discussed up to now can be implemented on the basis of this structure as follows: NNCs are a reflex of spec-head agreement. Krifka (1989), Ortmann (2000), Farkas and de Swart (2010), Bayirli (2017), Sağ (2018), Ionin and Matushansky (2018), among others, have proposed agreement-based approaches, though details of implementation differ. From their perspective, there are indeed two types of languages as in (30):

(30) Type I languages are plural agreement languages (English, German, etc.). Type II languages are not plural agreement languages (Hungarian, Turkish, etc.).

Thus, there is indeed a parameter, but of a different nature, similar to what we know from cases of subject-verb agreement (we are basically dealing with a morpho-syntactic parameter). Exactly as there are languages with overt subjectverb agreement, e.g. German, and languages without, e. g. Mainland Scandinavian, there are languages with and without plural agreement. Approaching the morpho-syntax of plurality from this perspective gains support from the observation that the same factors that establish verb-subject agreement are also involved in the context of NNC agreement. Ionin and Matushansky (2018) show that "plural marking on the lexical NP in cardinal-containing NPs and verbal agreement with such NPs can be conditioned by the same factors." We will review evidence for this in Section 6.1. This will be based on so-called plurality splits, already hinted at in Section 4.

Interestingly, this type of agreement is diachronically unstable. For instance, the situation in Hungarian has not always been as it is today. As reported in Horváth (2015), there was a lot of variation with respect to the presence of plurals after numerals starting from Old Hungarian up to the 19th century. This variation begins with a ratio of $50 \%-50 \%$ leading to complete disappearance of concord. The ratio differs depending on registers and even manuscripts. Interestingly, the ratio is different after numerals than other quantifiers, in support of a non-uniform treatment of numerals and quantifiers. It is not clear why plural 
appears after numerals in Hungarian, as this is a feature unexpected in Uralic languages, and maybe a Hungarian innovation, presumably due to the influence of Latin. ${ }^{8}$

\section{Type II languages}

\subsection{Agreement and differential marking effects}

Plurality splits is a term introduced in Smith-Stark (1974). It basically means that "for some nouns, plurality is distinguished from the singular, while for others the distinction may be irrelevant. Such a split may occur with respect to verbargument concord, and also noun-modifier concord.” (Smith-Stark 1974: 657; see also Corbett 2000). Such splits are generally linked to two hierarchies, the animacy hierarchy proper, (31-a) in Croft (2002: 130), and/or the definiteness hierarchy in (31-b):

a. human $>$ animate $>$ inanimate

b. definite $>$ specific $>$ non-specific

As has been noted in the literature, what we find is basically very similar to the conditions determining differential object marking (DOM) effects, discussed in Silverstein (1976), Bossong (1985), Aissen (2003) and many others. Let us consider some examples.

In Persian, the marker -an never applies to inanimates, which receive a special marker, namely - $h a$; the verb agrees obligatorily only with the animate noun phrase, as illustrated in (32).
a. Baradar-an-am nazde-u bud-an
(Persian)
brother-PL-POSS.1SG at-3SG.ANIM COP.PAST-3PL
'My brothers were with him.'
b. šaxe-ha šekast
branch-PL crack-PRET.3SG
'The branches broke.'

(Ortmann 2002: 157)

Western Armenian, as reported by Sigler (1996), obligatorily shows verb-subject plural agreement with definite noun phrases; Persian is similar (Ghomeshi 2003):

8 Many thanks to Barbara Egedi for discussions on this point. 

a. kәsan изапов кәпитеп-ә-тә сахове-с-аv
(Western Armenian) twenty student exam-ABL-INDEF fail-AOR.3SG 'Twenty students failed an exam.'
b. kasan иsапов-*(ner)-ə kәпиten-ә-тә сахове-с-аn twenty student- PL -DEF exam-ABL-INDEF fail-AOR-3PL 'The twenty students failed an exam.' (Sigler 1996: 167-168)

We saw above that in Turkish, plural can occur on nouns in the context of numerals, if the nouns are interpreted as definite, see (23). Kornfilt (1997) argues that non-specific subjects cannot control verbal agreement, as illustrated in (34).
a. Köy-ü haydut-lar bas-miş.
village-ACC robber-PL raid-REP.PST.3SG
'Robbers raided the village.'
b. Köy-ü haydut-lar bas-miş-lar.
village-ACC robber-PL raid-REP.PST.3PL
'The robbers raided the village.'
(Kornfilt 1997: 385)

(Turkish)

I have already mentioned that there is a correlation between plurality and animacy. As it has been reported in the literature, plural-verb agreement in Turkish is sensitive to animacy (Sezer 1978: 26), as shown in (35).

a. Animate plural subject:

Çilingir-ler kapı-lar-ı aç-tı-(lar).

(Turkish)

locksmith-PL door-PL-ACC open-PST-3PL

'Locksmiths opened the doors.'

b. Inanimate plural subject:

Anahtar-lar kapı-lar-l aç-tı-^lar.

key-PL door-PL-ACC open-PST-3PL

'Keys opened the doors.'

(Sezer 1978: 26)

More recently, Bamyac1 et al. (2014) point out that these distinctions are more fine-grained than previously assumed. Finally, in many Creoles plural marking is obligatory with animate and/or definite nouns (see Stolz 2007; Déprez 2005; Haspelmath and the APiCS Consortium 2013 and many others).

In the diachrony of Welsh, as Nurmio and Willis (2016) describe, the singular form in NNCs is the result of a re-interpretation of old dual and plural forms as singular due to the loss of final syllables. New plurals were formed to re-establish 
a singular-plural contrast but the NNC construction preserved the singular form with the exception of some nouns which had distinct forms in this context. This distinct form is labelled numerative and it is distinct from the singular and often also from the plural, as shown in (36). Importantly, nouns that can build numeratives are [+animate] and they resisted the spread of the singular in NNCs:

(36) un brawd 'one brother' dau froder 'two brothers' brodyr 'brothers' (Welsh) (Nurmio and Willis 2016: ex. [2b])

Summarizing, the presence of plurality in type II languages seems sensitive to semantic features, and differential marking (DM) effects emerge; DM effects thus suggest that plurality splits must be dealt with within a theory of agreement. In the next section, I turn towards an account of the patterns observed.

\subsection{The structure and agreement patterns of NNCs}

We have already discussed in Section 5.1 the various approaches to the syntax of NNCs: either they involve a Spec-head configuration, or a head-complement structure. The two structures are illustrated once again in (37), and see (24) and (25) above, adapted and slightly modified from Borer (2005) and Danon (2012):

(37) a. Numerals as specifiers

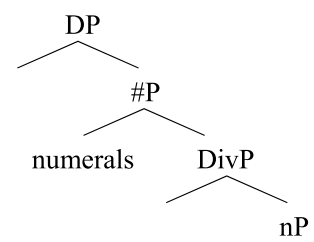

b. Numerals as heads

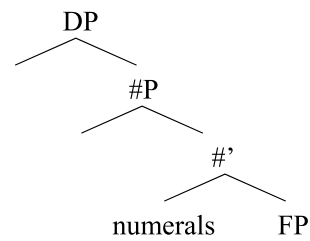

Evidence for the structure in (37-b) comes from languages where the noun following the numeral bears a case distinct from that of the numeral. A case in point is Finnish, discussed in Ionin and Matushansky (2006), Danon (2012), Brattico (2010, 2011), and Landau (2016) among others. In Finnish, demonstratives, which are situated above numerals in (38), bear plural marking. The distribution is as de- 
tailed in Landau (2016: 1005) as follows: numerals split the DP internal domain into two zones: above numerals and below numerals. Above numerals there is "semantic agreement in number and the structural case assigned from the outside (NOM or ACC); below numerals, elements show singular agreement and partitive case. Since an attributive adjective may attach in either domain, it may show either pattern." From the perspective of structure (37-b), this means that low adjectives are within the FP and thus agree with its head noun. High adjectives, however, are above \#P and thus show plural marking:

$$
\begin{aligned}
& \text { a. ne kaksi pilaantunut-ta leipä- } \ddot{a} \\
& \text { those.PL two.SG rotten-SG.PRT bread-SG } \\
& \text { b. ne pilaantune-et kaksi leipä-ä } \\
& \text { those.PL rotten-PL.ACc two.SG bread-SG } \\
& \text { 'those two rotten breads' } \\
& \text { (Landau 2016: 1005) }
\end{aligned}
$$

The presence of partitive case below numerals is suggestive of a structure along the lines of (37-b). Danon (2012) explicitly argues that in languages where the noun in NNCs bears case (partitive as in Finnish or genitive as in Russian) case assignment takes place directly from the numeral. In all other languages, NNCs have a structure as in (37-a). Thus, unlike as argued in Ionin and Matushansky (2006), NNCs in languages where no distinct case marking is observed involve numerals as specifiers in \#P.

Turning to Hungarian, Welsh and Turkish, as Ionin and Matushansky (2006) have argued, here the nominal morphology correctly reflects the semantic atomicity of the noun. Assuming we do not want to allow for a zero classifier to realize $\operatorname{Div}^{\circ}$, the most straightforward analysis to capture the absence of plural morphology in this case is to allow \#P to simply combine with nP, i. e. the structure lacks a DivP. As Borer (2013) argued, parts of the extended projection are optional, but their presence or absence has interpretational consequences, which are the DM effects in our case. When Div is present, it is realized as a classifier in Hungarian (26-b) or Turkish; alternatively, when Div is realized as plural in Turkish, a specific reading emerges, (23-b). This in turn means that in English, as Ionin and Matushanksy (2006: 326) stated, the presence of plural marking on nouns in NNCs is misleading, a simple morphological effect (cf. footnote 7).

Support for the presence of an nP in NNCs comes from the diachronic development of Welsh plural forms as detailed in Nurmio and Willis (2016). As already mentioned, in Welsh singular forms in NNCs are the result of a reanalysis of old plural and dual forms as singulars due to phonological changes. As a result of case and number marking, plural and dual forms became homophonous 
to singular ones. While the language created new plural forms to re-establish the singular-plural distinction, the result being that for many nouns there are two plural forms, in NNCs, the historically correct plurals were re-analyzed as singulars. We can make sense of this development by considering these historically correct plurals as lexical plurals in the sense of Acquaviva (2008) and Alexiadou (2011) and thus as forms realizing $\mathrm{n}$.

Let us now consider the workings of agreement in NNCs building on Landau's work. We can adopt the structure (37-a). As in Landau (2016), numerals are placed in \#P. If numerals are specifiers of \#P, they enter Spec-head agreement, in which case plural morphology realizes this agreement relationship in English, while this is not the case in e. g. Hungarian, Turkish, and Welsh. Across languages, we have two agreement zones divided by cardinal numerals: in the zone below numerals, we have CONCORD (morphological, non-semantic) agreement. In the zone above numerals, we have INDEX (semantic) agreement, see Landau (2016: 1006) for details. The proposal relies on the theory developed in Wechsler and Zlatić (2003), according to which the agreement system is dual, consisting of CONCORD (syntactic) and INDEX (semantic) features. Landau (2016) argues that both types of features are simultaneously present inside DPs, triggering DP-internal and external (DP-predicate) agreement. Building on this, the proposal is that in languages where we see the singular with numerals we have absence of index (semantic plural) agreement. By contrast, in English, as also put forth in Ionin and Matushansky (2006), the noun can enter INDEX agreement and thus surface with plural morphology. ${ }^{9}$

Focusing now on DM effects, two factors seem to play a role and relate to the hierarchical organization of features within the DP, as put forth in the work of Harley and Ritter (2002), see also Cowper and Hall (2002). These two factors are: presence vs. absence of gender and realization of (in-)definiteness. With respect to gender, type II languages that have DM effects lack gender. Di Garbo (2014: 130), building on Creissels et al. (2008), observes that "when gender marking is absent, number marking tends to remain optional. Plural markers tend to be used on a pragmatic basis." This is exactly what we have seen in our sample. This is similar to what we see in the area of DOM in relation to case-marking: as Anagnos-

9 The question that arises is why it is possible in languages such as English to have this type of agreement. Bayirli (2017) attributes this to the fact that in languages such as Turkish, the nP is a phase and thus agreement is blocked.

Note here that according to Landau (2016: 996), there is a third zone "introduced and bounded by $\mathrm{D}$. This is where DP-external agreement takes place. On the phase-based view adopted here, D is the exclusive 'contact point' between external probes (like v and T) and any nominal $\varphi$-features. This type of agreement targets INDEX features, perhaps universally so." 
topoulou (2017) points out, languages that lack gender show DOM effects that are related to specificity/definiteness.

The interaction between the features associated with the different layers in the structure in (37-a) is relevant in trying to understand the behavior of Standard English, Hungarian, and Welsh. Standard English is a type I language, although it lacks gender. I would like to propose that this is related to the fact that in English marking of (in)-definiteness is obligatory. As Gil (1987: 263) notes, "if a language has obligatory marking of (in)-definiteness then it has obligatory plural marking." This is the case in English, which lacks gender, but still shows obligatory marking of plurality at least in the standard varieties (see footnote 1). It is not clear whether languages such as Hungarian, Turkish or Welsh have obligatory marking of indefiniteness. Thus, these two factors provide us with a way to understand the puzzle. DM effects emerge when languages lack gender, and/or lack English type marking of (in-)definiteness. Specifically, if a language lexicalizes indefiniteness, then it will not show plurality splits along the two hierarchies.

Crucially, DM effects emerge as plurality takes over the function of either individuation (animacy) or identifiability (definiteness/specificity, see von Heusinger 2002) or both. The Turkish facts reported in Bliss (2004) are characteristic of this distribution. Individuation and identifiability are means to classify nouns, see Bisang (2017) for recent discussion. Individuation is performed in other languages by gender (Kramer 2015; Anagnostopoulou 2017), identifiability by D (Alexiadou et al. 2007 for an overview). There is an incremental relation between the two, as pointed out in Anagnostopoulou (2017). Number is ideally located in the structure in (37-a) to perform these functions, as it is above individuation in $\mathrm{n}$ and below identifiability in D. In the absence of gender (class), situated in n, number provides individuation leading to animacy splits. In cases where $\mathrm{D}$ instead of gender provides individuation, we have definiteness or specificity splits (related to the absence of an overt D, see Kim [2008], or the particular features located in D). In most cases the two are correlated, as shown by the Turkish data discussed here and is also shown by Kim (2008) for Korean, Chinese and Japanese, a set of languages that I have not discussed up to now. Hungarian seems to be the case where we have complete grammaticalization and no sensitivity to semantic features, as discussed also in Ortmann (2002).

Let me briefly outline Kim's (2008) analysis. Kim's claim is that in classifier languages such as Chinese, Japanese and Korean, which use classifiers in the context of numerals, the plural marker does more that in languages like English. First of all, plural marking is present in the context of animate nouns. However, it is not simply a marker of animacy. Rather it correlates with identifiability. In particular, while it correlates with marking of definiteness in Chinese and Japanese, it correlates with specificity in Korean. Kim's analysis is based on the article choice 
parameter proposed in Ionin et al. (2004), see also Julien (2005) for Scandinavian:

(39) A language which has two articles distinguishes them as follows:

The Definiteness Setting: Articles are distinguished on the bases of definiteness.

The Specificity Setting: Articles are distinguished on the bases of specificity.

Building on this, Kim proposes the following plural marking parameter:

(40) The plural markers of classifier languages are characterized as follows:

The Definiteness Setting: Plural markers mark definiteness.

The Specificity Setting: Plural markers mark specificity.

We can extend this view to some of the languages in our sample, which are all (optional) classifier languages. ${ }^{10}$ What is important, however, and predicted by Landau's (2016) dual system is that when Number aligns with D obligatory agreement in the context of numerals may surface, as is the case in Western Armenian, as shown in (41), and we saw for Turkish in (23) and (34) above:

a. Yergu dagha-ner vaze-ts-in.

(Western Armenian)

two boy-PL run-PST-3PL

'Two boys ran.'

b. *Yergu dagha-n vaze-ts.

two boy(SG)-DEF run-PST

'The two boys ran.'

c. Yergu dagha-ner-a vaze-ts-in.

two boy-PL.DEF run-PST.3PL

'The two boys ran.'

(Bale and Khanjian 2014: 7-8)

We can also extend Kim's (2008) parameter to capture the animacy alignment: if a language lacks gender, and overt marking of (in-)definiteness, plural marking will be sensitive to animacy and definiteness/specificity, due to the incremental relation of features within the DP in the structure in (24) and (37-a). Importantly, such effects are only possible in languages which lack semantic agreement within the DP and fail to lexicalize D, as explained above. Thus, while absence of

10 It is not crucial for the implementation as to whether specificity and definiteness are both hosted in $\mathrm{D}^{\circ}$ in our structure in (24) or split into two distinct functional layers. 
gender is the unifying feature in establishing the low zone in (24), as it is found both in Hungarian, varieties of English and Turkish, only Turkish shows DM effects.

Further evidence for the way features interact DP internally comes from two languages that seem to present a counterargument to the generalization concerning NNCs, gender and D, namely Miya and Welsh. Miya, a Chadic language, described in Schuh (1989), has optional marking of plurality for [-animate] nouns, while [+animate] nouns are obligatorily marked for plural. The language has a gender system, and unlike other Chadic languages in the context of numerals nouns bear morphological plural. This conforms to the situation found in type I languages, while its animacy split does not. According to Schuh, however,

\footnotetext{
Miya retains an active gender system, yet there are no morphological or phonological cues on the nouns themselves as to their gender. Indeed, Miya has gone in the opposite direction from those languages - other Chadic languages with an active gender system AA - where a gender/number agreement system has given way to a simple singular/plural distinction. In Miya, the largest class of nouns, the [-animate] class, requires agreement with underlying, lexical gender rather than morphological or semantic number. (Schuh 1989: 179)
}

The strong correlation between gender and plurality is accounted for in Kramer's (2015) system by locating gender features on $n$.

Welsh also has a two-gender system (Borsley et al. 2007) but disallows plural forms in NNCs. ${ }^{11}$ As I noted above, DM effects seem to have played a role in the diachrony of Welsh, as plurality is preserved in NNCs with [+animate] nouns. However, as I also noted, this system is the result of a reanalysis of plurality as an exponent of n. Nevertheless, as Hammond (2016) argues in detail, and in a sense similar to Miya, the only strategy to determine gender on Welsh nouns is guess masculine, which would be correct for $64 \%$ of the nouns found in electronic corpora of Welsh such as the Cronfa electroneg o Gymraeg (Ellis et al. 2001). It is thus interesting that Miya and Welsh seem to confound gender distinctions and show gender-plurality interactions that are suggestive of an $\mathrm{nP}$ type split.

\section{Conclusions}

In this contribution, I have argued that plural is universally semantically unmarked. Plural marking is an example of mismatch between complexity in form

11 Many thanks to Maria Kouneli for discussion on this point. 
and specification in meaning (see also the discussion in Sauerland 2008). This mismatch is not really restricted to some particular group of languages and is independent of form of plurality (affixal, reduplication, etc.) I have argued that the plural has the same morpho-syntactic re-presentation across languages. I have also argued that the co-occurrence of plural with numerals is an agreement phenomenon, although it is possible that the syntax of numerals differs (head vs. specifier), yielding partitive constructions for NNCs in some languages. A dual agreement system as the one put forth in Landau (2016) can account for the agreement patterns observed.

Moreover, I discussed plurality DM effects, which differ across languages along the lines of DM effects in other domains (animacy, definiteness/specificity, or both). I have argued that these DM effects emerge via the hierarchical organization of features in the DP structure, and are related to noun classification.

This contribution has furthermore made a case that experimental and detailed theoretical cross-linguistic investigation is necessary in order to identify the core meaning of plurality and number in general. I have shown that the relationship between morphology and interpretation might be a bit more complicated than we think (at least for number). Understanding this relationship is an important step towards the development of a morpho-semantic theory of number. While I agree with Jespersen (1924: 283) that "number might appear to be one of the simplest natural categories. Yet on closer inspection it presents a great many difficulties, both logical and linguistic," I believe that collaborative research will be of vital importance in dealing with and overcoming these difficulties.

Acknowledgment: Earlier versions of this paper have been presented at various workshops and seminars in Trondheim, Barcelona, Bochum, Utrecht, and Berlin as well as at the 23rd International Symposium on Theoretical and Applied Linguistics (ISTAL) in Thessaloniki (March 2017) and the 40th Annual Conference of the German Linguistic Society (DGfS) in Stuttgart (March 2018). I am indebted to all these audiences for their comments. Special thanks to Uli Sauerland and Kazuko Yatsushiro, who have heavily influenced my thinking about plurality as well as to Florian Schwarz for proposing to run experiments on Turkish. I am grateful to Elena Anagnostopoulou, Terje Lohndal, Maria Kouneli, Ora Matushansky and George Tsoulas for discussions on various issues. Many thanks to the editors of this journal for their insightful comments that greatly improved the readability of this paper. AL 554/8-1 is hereby acknowledged. 


\section{Abbreviations in glosses}

1, 2, 3 1st, 2nd, 3rd person

ABL ablative

ACC accusative

ANIM animated

AOR aorist

$\mathrm{AV}$ agentive voice

CL classifier

COP copula

DAT dative

DEF definite

IMP imperative

INDEF indefinite

NEG negation, negative

PASS passive voice

PAST / PST past tense

PL plural

Poss possessive

PRET preterite tense

PRT partitive case

REDUP reduplication

REL relative-clause marker

REP reported evidential

SG singular

\section{References}

Acarlar, Funda \& Judith Johnston. 2011. Acquisition of Turkish grammatical morphology by children with developmental disorders. International Journal Language and Communication Disorders 46(6). 727-738.

Ackles, Nancy. 1997. Historical syntax of the English article in relation to the count/non-count distinction. Seattle, WA: University of Washington dissertation.

Acquaviva, Paolo. 2008. Lexical plurals. Oxford: Oxford University Press.

Aissen, Judith. 2003. Differential object marking: Iconicity vs. economy. Natural Language and Linguistic Theory 21(3). 435-483.

Alexiadou, Artemis. 2011. Plural mass nouns and the morpho-syntax of number. In Mary B. Washburn, Katherine McKinney-Bock, Erika Varis, Anne Sawyer \& Barbara Tomaszewicz (eds.), Proceedings of the 28th West Coast Conference on Formal Linguistics, 33-41. Somerville, MA: Cascadilla Press. 
Alexiadou, Artemis. to appear. On plurals and plurality. Selected Papers on Theoretical and Applied Linguistics from ISTAL, Thessaloniki, 31 March - 2 April 2017.

Alexiadou, Artemis, Liliane Haegeman \& Melita Stavrou 2007. Noun phrase in the generative perspective. Berlin \& New York: de Gruyter Mouton.

Anagnostopoulou, Elena. 2017. Accusative case morphology conditioned by gender. Paper presented at the David Pesetsky@60 Panel on Case. MIT, February 11, 2017. http://crete. academia.edu/ElenaAnagnostopoulou/ (08.02.2019).

Aronoff, Mark \& Kirsten Fudeman. 2011. What is morphology? Oxford: Blackwell.

Arka, Wayan I. \& Mary Dalrymple. 2017. Nominal, pronominal, and verbal number in Balinese. Linguistic Typology 21(2). 261-331.

Bale, Alan, Michael Gagnon \& Hrayr Khanjian. 2011a. Crosslinguistic representations of numerals and number marking. Semantics and Linguistic Theory 20.582-598. DOI: 10.3765 /salt.v20i0.2552.

Bale, Alan, Michael Gagnon \& Hrayr Khanjian. 2011b. On the relationship between morphological and semantic markedness: The case of plural morphology. Morphology 21(1). 197-221.

Bale, Alan \& Hrayr Khanjian. 2014. Syntactic complexity and competition: The singular-plural distinction in Western Armenian. Linguistic Inquiry 45(1). 1-26.

Bamyacı, Elif, Jana Häussler \& Bariş Kabak. 2014. The interaction of animacy and number agreement: An experimental investigation. Lingua 148. 254-277.

Bayirli, Isa Kerem. 2017. The universality of concord. Cambridge, MA: MIT dissertation.

Bisang, Walter. 2017. Classification between grammar and culture: A cross linguistic perspective. In Tanja Pommerening \& Walter Bisang (eds.), Classification from antiquity to modern times: Sources, methods, and theories from an interdisciplinary perspective, 199-230. Berlin \& Boston: de Gruyter Mouton.

Bliss, Heather. 2004. The semantics of the bare noun in Turkish. Calgary (Working) Papers in Linguistics 25. DOI: 10.11575/PRISM/28976.

Borer, Hagit. 2005. In name only. Oxford: Oxford University Press.

Borer, Hagit. 2013. Taking form. Oxford: Oxford University Press.

Borsley, Robert, Maggie Tallerman \& David Willis 2007. The syntax of Welsh. Cambridge: Cambridge University Press.

Bouchard, Denis. 2002. Adjectives, number and interfaces: Why languages vary. Amsterdam: Elsevier.

Bossong, Georg. 1985. Differentielle Objektmarkierung in den neuiranischen Sprachen. Tübingen: Gunter Narr.

Brattico, Pauli. 2010. One-part and two-part models of nominal case: Evidence from case distribution. Journal of Linguistics 46(1). 47-81.

Brattico, Pauli. 2011. Case assignment, case concord, and the quantificational case construction. Lingua 121(6). 1042-1066.

Chemla, Emmanuel. 2008. An epistemic step for anti-presuppositions. Journal of Semantics 25(2). 141-173.

Cheshire, Jenny, Jacomine Nortier \& David Adger. 2015. Emerging multi-ethnolects in Europe. Queen Mary's Occasional Papers Advancing Linguistics 33.

Clark, Eve \& Tatiana V. Nikitina. 2009. One vs. more than one: Antecedents to plural marking in early language acquisition. Linguistics 47(1). 103-139.

Corbett, G. Greville. 2000. Number. Cambridge: Cambridge University Press.

Cowper, Elizabeth \& Daniel Curie Hall. 2002. The syntactic manifestation of nominal feature 
geometry. In Sophie Burelle \& Stanca Somesfalean (eds.), Proceedings of the 2002 Annual Conference of the Canadian Linguistic Association, 55-66. Montréal, QC: Cahiers linguistiques de l'UQAM.

Creissels, Denis, Gerrit J. Dimmendaal, Zygmut Frajzyngier \& Christa König. 2008. Africa as a morphosyntactic area. In Bernd Heine \& Derek Nurse (eds.), A linguistic geography of Africa, 86-150. Cambridge: Cambridge University Press.

Croft, William. 2002. Typology and universals. Second Edition. Cambridge: Cambridge University Press.

Danon, Gabi. 2012. Two structures for numeral-noun constructions. Lingua 122(12). 1282-1307.

Dékany, Eva. 2011. A profile of the Hungarian DP. Tromsø: University of Tromsø dissertation.

Déprez, Viviane. 2005. Morphological number, semantic number and bare nouns. Lingua 115(6). 857-883.

Di Garbo, Francesca. 2014. Gender and its interaction with number and evaluative morphology. Stockholm: Stockholm University dissertation.

van Eijck, Jan. 1983. Discourse representation theory and plurality. In Alice ter Meulen (ed.), Studies in modeltheoretic semantics, 85-106. Dordrecht: Foris.

Ellis, Nick C., Cahill O’Dochartaigh, William Hicks, Menna Morgan \& Nadine Laporte. 2001. Cronfa Electroneg o Gymraeg (CEG): A 1 million word lexical database and frequency count for Welsh. [On-line]. www.bangor.ac.uk/canolfanbedwyr/ceg.php.en (08.02.2019).

Farkas, Donka F. \& Henriëtte E. de Swart. 2003. The semantics of incorporation: from argument structure to discourse transparancy. Stanford, CA: CSLI Publications.

Farkas, Donca F. \& Henriette E. de Swart. 2010. The semantics and pragmatics of plurals. Semantics and Pragmatics 3. 1-54. Article 6: DOI: 10.3765/sp.3.6.

Ghomeshi, Jila. 2003. Plural marking, indefiniteness, and the noun phrase. Studia Linguistica 57(2). 47-74.

Gil, David. 1987. Definiteness, noun phrase configurationality, and the mass-count distinction. In Eric Reuland \& Alice ter Meulen (eds.), The representation of indefiniteness, 254-269. Cambridge, MA: MIT Press.

Giusti, Giuliana 2002. The functional structure of noun phrases: A bare phrase structure approach. In Guglielmo Cinque (ed.), Functional structure in DP and IP, 54-90. 0xford: Oxford University Press.

Greenberg, H. Joseph. 1963. Some universals of grammar with particular reference to the order of meaningful elements. In Joseph Greenberg (ed.), Universals of language, 73-113. 2nd edn. Cambridge, Mass: MIT Press.

Greenberg, H. Joseph. 1966. Language universals, with special reference to feature hierarchies. The Hague: Mouton.

Greenberg, H. Joseph. 1974. Numeral classifiers and substantival number: Problems in the genesis of a linguistic type. In Luigi Heilmann (ed.), Proceedings of the Eleventh International Congress of Linguists, 17-37. Bologna: il Mulino.

Harbour, Daniel. 2008. Morpho-semantic number. Dordrecht: Springer.

Hammond, Michael. 2016. Predicting the gender of Welsh nouns. Corpus Linguistics and Linguistic Theory 12(2). 221-262.

Harley, Heidi \& Elizabeth Ritter. 2002. Person and numbers in pronouns: A feature-geometric analysis. Language 78(3). 482-526.

Haspelmath, Martin. 2006. Against markedness and what to replace it with. Journal of Linguistics 42(1). 25-70.

Haspelmath, Martin \& the APiCs Consortium. 2013. Occurrence of nominal plural markers. In 
Susanne M. Michaelis, Philippe Maurer, Martin Haspelmath \& Magnus Huber (eds.), The atlas of Pidgin and Creole language structures, 84-87. Oxford: Oxford University Press. Haspelmath, Martin \& Andres Karjus. 2017. Explaining asymmetries in number marking: Singulatives, pluratives and usage frequency. Linguistics 55(6). 1213-1235.

Heim, Irene. 1991. Artikel und Definitheit. In Arnim von Stechow \& Dieter Wunderlich (eds.), Semantik / Semantics - Ein internationales Handbuch der zeitgenössischen Forschung / An international handbook of contemporary research, 487-535. Berlin \& New York: de Gruyter.

von Heusinger, Klaus. 2002. Specificity and definiteness in sentence and discourse structure. Journal of Semantics 19(3). 245-274.

Heycock, Caroline \& Roberto Zamparelli. 2005. Friends and colleagues: Plurality, coordination, and the structure of DP. Natural Language Semantics 13(3). 201-270.

Hoeksema, Jack. 1983. Plurality and conjunction. In Alice ter Meulen (ed.), Studies in modeltheoretic semantics, 63-83. Dordrecht: Foris.

Horváth, László. 2015. Két korpuszok vallomása [The testimony of two corpora]. Magyar nyelvör 139. 477-491.

Iordăchioaia, Gianina, Artemis Alexiadou \& Andreas Pairimadis. 2017. Morpho-syntactic sources for synthetic compounds in English and Greek. Zeitschrift für Wortbildung/Journal of Word Formation 1(1). 47-72.

Ionin, Tania, Heejeong Ko \& Ken Wexler. 2004. Article semantics in L2 acquisition: The role of specificity. Language Acquisition 12(1). 3-69.

Ionin, Tania \& Ora Matushansky. 2006. The composition of complex cardinals. Journal of Semantics 23(4). 315-360.

Ionin, Tania \& Ora Matushansky. 2018. Cardinals. The syntax and semantics of cardinal-containing expressions. Cambridge, MA: MIT Press.

Jakobson, Roman. 1968. Child language, aphasia and phonological universals. The Hague: Mouton.

Jakobson, Roman. 1971. Shifters, verbal categories, and the Russian verb. In Roman Jakobson (eds.), Selected writings, vol. 2: Word and language, 130-147. The Hague: Mouton. Jespersen, Otto. 1924. The philosophy of grammar. London: Allen \& Unwin.

Julien, Marit. 2005. Nominal phrases from a Scandinavian perspective. Amsterdam: Benjamins. Kihm, Alan. 2007. On the interpretation of bare noun phrases in Guinea-Bissau Portguese. In Marlyse Babtista \& Jacquelie Guéron (eds.), Noun phrases in Creole languages: $A$ multi-faceted approach, 145-170. Amsterdam: Benjamins.

Kim, Jaeshil. 2008. The parameterization of plural markings in classifier languages. Kansas Working Papers in Linguistics 30. 159-173.

Kiparsky, Paul \& Judith Tonhauser. 2012. Semantics of inflection. In Claudia Maienborn, Klaus von Heusinger \& Paul Portner (eds.), Semantics: An international handbook of natural language meaning, vol. III, 2070-2097. Berlin \& New York: de Gruyter Mouton.

Kramer, Ruth. 2015. The morpho-syntax of gender. Oxford: Oxford University Press.

Krifka, Manfred. 1989. Nominal reference, temporal constitution and quantification in event semantics. In Renate Bartsch, Johan van Benthem \& Peter van Emde Boas (eds.), Semantics and contextual expression, 75-115. Dordrecht: Foris.

Kornfilt, Jaklin. 1997. Turkish. New York: Routledge.

Kortmann, Bernd \& Kerstin Lunkenheimer (eds.). 2013. The electronic world atlas of varieties of English. Leipzig: Max Planck Institute for Evolutionary Anthropology. http://ewaveatlas.org (08.02.2019). 
Kurumada, Chigusa \& Scott Grimm 2017. Communicative efficiency in language production and learning: Optional plural marking. In Glenn Gunzelmann, Andrew Howes, Thora Tenbrink \& Eddy Davelaar (eds.), Proceedings of the 39th annual meeting of the Cognitive Science Society, 2500-2506. Austin, TX: Cognitive Science Society.

Landau, Idan. 2016. DP internal agreement: A configurational analysis. Natural Language and Linguistic Theory 34(3). 975-1020.

Marti, Luisa. 2017. Inclusive plural and the theory of number. Ms., Queen Mary University of London.

Mathieu, Eric. 2014. Many a plural. In Ana Aguilar-Guevara, Bert Le Bruyn \& Joost Zwarts (eds.), Weak referentiality, 157-182. Amsterdam: Benjamins.

Mittendorf, Ingo \& Louisa Sadler. 2005. Numerals, nouns and number in Welsh NPs. In Miriam Butt \& Tracy Holloway King (eds.), Proceedings of the LFG '05 Conference, 294-312. Stanford, CA: CSLI Publications.

Nurmio, Silvia \& Davis Willis. 2016. The rise and fall of a minor category: The case of the Welsh numerative. Journal of Historical Linguistics 6(2). 297-339.

Ortmann, Albert. 2000. Where plural refuses to agree: feature unification and morphological economy. Acta Linguistica Hungarica 47(1-4). 249-288.

Ortmann, Albert. 2002. Economy-based splits, constraints, and lexical representations. In Ingrid Kaufmann \& Barbara Stiebels (eds.), More than words: A festschrift for Dieter Wunderlich, 147-178. Berlin: Akademie Verlag.

Pearson, Hazel A., Manizeh Khan \& Jesse Snedeker. 2011. Even more evidence for the emptiness of plurality: An experimental investigation of plural interpretation as a species of implicature. Semantics and Linguistic Theory 20. 489-507. DOI: 10.3765/salt.v20i0.2554.

Poplack, Shana \& Sali Tagliamonte. 1994(3). $\underline{-S}$ or nothing: Marking the plural in African-American Diaspora. American Speech 69. 227-259.

Renans, Agata, George Tsoulas, Raffaella Folli, Nihan Ketrez, Lyn Tieu, Hanna H. de Vries \& Jacopo Romoli. 2017. Turkish plural nouns are number-neutral: Experimental data. In Alexandre Cremers, Thom van Gessel \& Floris Roelofsen (eds.), Proceedings of the 21st Amsterdam Colloquium 2017, 365-374. Amsterdam: ILLC.

Rijkhoff, Jan. 2002. The noun phrase. Oxford: Oxford University Press.

Sağ, Yağmur. 2018. The semantics of numeral constructions in Turkish. In Uli Sauerland \& Stephanie Solt (eds.), Proceedings of Sinn und Bedeutung 22, vol. 2 (ZASPiL 61), 307-324. Berlin: ZAS.

Sauerland, Uli. 2003. A new semantics for number. Semantics and Linguistic Theory 13. 258-275. DOI: 10.3765/salt.v13i0.2898.

Sauerland, Uli. 2008. On the semantic markedness of $\Phi$-features. In Daniel Harbour, David Adger \& Susana Bejar (eds.), Ф-Features, 57-82. Oxford: Oxford University Press.

Sauerland, Uli, Jan Anderssen \& Kazuko Yatsushiro. 2005. The plural is semantically unmarked. In Stefan Kepser \& Marga Reis (eds.), Linguistic evidence. Empirical, theoretical and computational perspectives, 409-430. Berlin \& New York: de Gruyter Mouton.

Sezer, Engin. 1978. Eylemlerin çoğul öznelere uyumu [The agreement between verbs and plural subjects]. Genel Dilbilim Dergisi 1. 25-32.

Sigler, Michele. 1996. Specificity and agreement in Standard Western Armenian. Cambridge, MA: MIT dissertation.

Silverstein, Michael. 1976. Hierarchy of features and ergativity. In R. M. W. Dixon (ed.), Grammatical categories in Australian languages, 112-171. Canberra: Australian Institute of 
Aboriginal Studies.

Silverstein, Michael. 1986. Hierarchy of features and ergativity. In Pieter Muysken \& Henk van Riemsdijk (eds.), Features and projections, 163-232. Dordrecht: Foris.

Schuh, Russel. 1989. Gender and number in Miya. In Zygmunt Frajzyngier (ed.), Current progress in Chadic linguistics, 171-181. Amsterdam: Benjamins.

Smith-Stark, Thomas-Cedric. 1974. The plurality split. In Michael W. La Galy, Robert A. Fox \& Anthony Bruck (eds.), Papers from the 10th regional meeting of the Chicago Linguistic Society, 657-671. Chicago, IL: Chicago Linguistic Society.

Spector, Benjamin. 2007. Aspects of the pragmatics of plural morphology: On higher-order implicatures. In Uli Sauerland \& Penka Stateva (eds.), Presuppositions and implicatures in compositional semantics, 243-281. Dordrecht: Springer.

Stolz, Thomas. 2007. Lexical typology, language contact and creolization. In Wiltrud Mihatsch \& Monika Sokol (eds.), Language contact and language change in the Caribbean and beyond/Lenguas en contacto y cambio lingüístico en el Caribe y más allá, 19-36. Frankfurt am Main: Peter Lang.

Szöke, Bernadett. 2018. Appositive constructions. In Gábor Alberti \& Tibor Laczkó (eds.), The syntax of Hungarian, vol. 1: Nouns and noun phrases, 896-931. Amsterdam: Amsterdam University Press.

Underhill, Robert. 1979. Turkish grammar. Cambridge, MA: MIT Press.

Wechsler, Stephen \& Larisa Zlatić. 2003. The many faces of agreement. Stanford, CA: CSLI Publications.

Wiltschko, Martina. 2008. The syntax of non-inflectional plural marking. Natural Language and Linguistic Theory 26(3). 639-694.

Yatsushiro, Kazuko. 2008. Quantifier acquisition: Presuppositions of every. In Atle Grønn (ed.), Proceedings of Sinn und Bedeutung 12, 663-677. Oslo: University of Oslo.

Yatsushiro, Kazuko, Uli Sauerland \& Artemis Alexiadou. 2017. The unmarkedness of plural: Crosslinguistic data. In Maria LaMendola \& Jennifer Scott (eds.), BUCLD 41: Proceedings of the 41st annual Boston University Conference on Language Development, 753-765. Somerville, MA: Cascadilla Press.

Yatsushiro, Kazuko, Artemis Alexiadou, Vasfiye Geckin, Veronika Harmati-Pap \& Uli Sauerland. 2018. The plural is unmarked. Paper presented at the OASIS Workshop on Nominal Phrase Meaning, Humboldt University, Berlin, January 11-12, 2018. https://www.angl.huberlin.de/research/respro/RUESHeL/events/nominal-phrase-meaning/sauerland-et-alslidesoasis2018.pdf (08.02.2019). 